\title{
Participación política juvenil: concepciones de las personas jóvenes participantes en seis agrupaciones de Costa Rica
}

\author{
Youth political participation: conceptions of young people participating in six groups of Costa Rica \\ Adrián Calvo Ugalde ${ }^{1}$ \\ Adriana Muñoz Amores ${ }^{2}$
}

Fecha de recepción: 3-05-2019

Fecha de aceptación: 12-04-2021

\begin{abstract}
Resumen
Este artículo recupera los principales resultados obtenidos por medio de la investigación cualitativa desarrollada como trabajo final de graduación para optar por el grado de Licenciatura en Trabajo Social de la Sede de Occidente, Universidad de Costa Rica; la cual se denominó: Participación política juvenil: un estudio exploratorio con agrupaciones juveniles existentes en el distrito central del cantón de San Ramón, Alajuela, en el periodo 2010-2011. Específicamente, se centra la atención en exponer las concepciones que tienen las personas jóvenes integrantes de seis agrupaciones juveniles sobre la participación política, con el propósito de comprender desde dónde parten para interpretar la realidad y desarrollar sus acciones colectivas en la formación social costarricense. Se concluye que coexisten tanto posiciones alternativas como tradicionales a la hora de definir el concepto de participación política. Además, se afirma que factores externos como la escuela, familia, relación de pares y las características de la agrupación en la cual se participa van a influenciar en las visiones de mundo de cada joven y en las acciones participativas que se desarrollan.
\end{abstract}

Palabras clave: participación política, agrupaciones juveniles, participación política juvenil, adultocentrismo, juventudes.

\begin{abstract}
This article recovers the main results obtained through qualitative research developed as final graduation work to opt for the degree in Social Work from the Sede de Occidente, University of Costa Rica; which is called: Youth political participation: an exploratory study with affected youth groups in the central district of the San Ramón canton, Alajuela, in the period 2010-2011. Specifically, attention is focused on exposing the conceptions that young people from six youth groups have about youth political participation, with the purpose of understanding where they start from to interpret reality and develop their collective actions in Costa Rican social formation. It is concluded that both alternative and traditional positions coexist when defining the concept of political participation. In addition, it is affirmed that external factors such as school, family, peer relationship and the characteristics of the group in which they participate will influence the world views of each young person and the participatory actions that are developed.
\end{abstract}

Keywords: political participation, youth groups, youth political participation, adult centrism, youth.

$1 \quad$ Licenciado en Trabajo Social por la Universidad de Costa Rica, Máster en Estudio de la Violencia Social y Familiar por la Universidad Estatal a Distancia, Costa Rica. Docente e investigador de la Universidad de Costa Rica, Sede de Occidente, Departamento de Ciencias Sociales. Correo electrónico: adrian.calvougalde@ucr.ac.cr

2 Licenciada en Trabajo Social por la Universidad de Costa Rica, Costa Rica. Docente e investigadora de la Universidad de Costa Rica, Sede de Occidente, Departamento de Ciencias Sociales. Correo electrónico: adrianapatricia.munoz@ucr.ac.cr 


\section{Introducción}

La estructura sociocultural establecida dentro de la sociedad llamada adultocentrismo ha centralizado la participación en el grupo etario constituido por las personas adultas, a las cuales se les identifica como el ser humano que posee las capacidades necesarias y el grado de madurez óptimo para tomar las decisiones más importantes en relación con la familia, la comunidad y el país.

Este sistema adultocéntrico ha provocado que no exista el interés de registrar o conocer las formas de participación ejercidas por las personas jóvenes, generando como consecuencia que en Costa Rica, tanto a nivel nacional como local, no haya información referente a la cantidad de grupos de jóvenes, el papel que desempeñan, sus acciones, funciones y tipo de participación realizada, entre otros aspectos vinculados con el mundo juvenil. Esta realidad fue identificada en el distrito central del cantón de San Ramón, donde se realizó el estudio.

Es así como, desde un enfoque inclusivo de las generaciones, se pretende destacar la participación política juvenil para visibilizar a las personas jóvenes como sujetos sociales proactivos en el espacio local.

Desde esta perspectiva, las personas jóvenes participantes, en la presente investigación cualitativa, fueron motivadas a brindar sus conocimientos, razonamientos o formas de pensar sobre la participación política, realizando un reconocimiento del aporte empírico de las juventudes desde su experiencia práctica en el contexto inmediato en el que habitan. Mediante lo anterior, se efectuó una construcción y apropiación del concepto de participación política juvenil que se abordará en los siguientes apartados.

\section{Aproximaciones teóricas para comprender la participación política juvenil}

En este apartado, se presentan las principales categorías de análisis que orientaron el proceso de acercamiento a las concepciones de la participación política juvenil de las agrupaciones involucradas en el proceso investigativo.

\subsection{Matriz adultocéntrica:}

El adultocentrismo es una matriz que se caracteriza y determina por medio de la dominación de las personas adultas sobre las jóvenes, donde se desarrollan conductas de subordinación o inferioridad, lo que produce una imagen social de un ser humano incompleto ante la sociedad (Duarte, 2006). Así, la persona adulta es situada como el modelo a seguir, por considerarse completo, maduro, responsable, preparado para la toma de decisiones, con capacidades de participación y perteneciente a la población económicamente activa.

Esta desigualdad, desarrollada por la matriz adultocéntrica, condiciona las acciones que pueden ejercer las personas jóvenes y la percepción que se va construyendo sobre ellas en la sociedad. Lo anterior, provoca una forma de exclusión social que se evidencia en frases como: la juventud es una etapa de preparación hacia la vida adulta; construyéndose un sistema de relaciones de poder que, al igual que el patriarcado, sobrevalora (subvalora) a un grupo social, en este caso las personas jóvenes.

De allí se fortalece la corriente de dominación llamada matriz adultocéntrica, la cual: "designa en nuestras sociedades una relación asimétrica y tensional de poder entre las personas adultas (+) y las jóvenes (-). Esta visión del mundo está montada sobre un universo simbólico y un orden de valores propios de la concepción patriarcal" (Arévalo, citado por Krauskopf, 2003, p. 17).

De lo anterior, es importante aclarar que la autora plantea con el signo positivo (+) la adjudicación de mayor poder al hombre adulto dentro de la familia y sociedad, en su condición de superioridad por el estatus quo que se le ha atribuido en las estructuras patriarcales. En estas estructuras se les dota de herramientas para ejercer control sobre los demás grupos poblacionales, llámense estos: infantes, jóvenes, mujeres o adultos mayores.

Por el otro lado, se les impone a las personas jóvenes un signo negativo (-), el cual se vincula a la dotación de una serie de estereotipos sociales que limitan su accionar social, político y económico. Esto reduce su pensamiento 
autónomo y suministra todo tipo de cargas que deben cumplirse de acuerdo con las órdenes de los mayores, las cuales lo llegarán a dotar de las características necesarias para obtener las responsabilidades de la vida adulta.

Con este razonamiento concuerdan autores como Duarte (2006), al afirmar que las significaciones otorgadas a las personas jóvenes a través de la historia se basan en relaciones desiguales. No obstante, no debe "crucificarse" lo adulto por ser adulto, sino que se debe buscar criticar y minimizar aquellas acciones o pensamientos que discriminen y rechacen lo juvenil.

Por ello, el adultocentrismo puede ser identificado con la reproducción de estereotipos y valorizaciones de rechazo y discriminación, traducido en la reducción de lo juvenil. Relacionado a la "juvenilización"3 que determina a las personas jóvenes con elementos estéticos y superficiales, reduciendo su pensamiento a la fiesta, el disfrute, las diversiones, entre otros, con una proyección de dicho grupo social como seres humanos incapaces de asumirse autónomos dentro de las relaciones sociales y con conductas irresponsables.

Es a partir de lo anterior, que se puede plantear que la matriz adultocéntrica proporciona elementos claves para comprender los procesos de estigmatización y discriminación hacia las juventudes, debido a que revela la condición histórica de subordinación de las generaciones nuevas a las maneras que impone el mundo adulto. En estas jerarquías, se les minimiza a los jóvenes sus capacidades, destrezas y habilidades para insertarse a la escena pública y política, además, se les excluye de la toma de decisiones que se relacionan con la mejora de sus condiciones y calidad de vida.

\subsection{Juventudes}

La internalización de roles, que impuso la cultura adultocéntrica desde sus inicios, trajo como consecuencia que las personas jóvenes fueran conceptualizadas a partir del razonamiento de las personas adultas, dejando de lado el conocimiento empírico de su verdadera realidad social.

Por lo tanto, el recorrido de la conceptualización ha pasado desde posturas tradicionales, que invisibilizan el papel de las personas menores dentro de las relaciones sociales, hasta posiciones teóricas más progresistas que idealizaron el ser joven, atribuyéndole caracterizaciones altruistas descontextualizadas de la realidad. Ambas, en determinados instantes, suelen: "deshistorizar las producciones juveniles" (Duarte, 2006, p. 178), al no ubicarlas en un contexto sociocultural e histórico, del cual forman parte y que influye en su construcción identitaria.

Por lo tanto: "ser joven es una construcción socio histórica que va más allá de la cantidad de años" (Duarte, 1998, p. 9). Se adscribe a la influencia directa de una serie de cambios políticos, económicos, sociales y culturales que modifican comportamientos, percepciones, ideologías y actitudes que se poseen acerca de estas personas dentro de la sociedad.

Autores como Margulis, Urresti, Duarte y Zúñiga han trabajado con base en sus experiencias con jóvenes para definir un concepto articulador de la historia y la diversidad, reconociendo que: "la significación de "juventud" se revela como sumamente compleja, proclive a las ambigüedades y simplificaciones" (Margulis, citado por Donas, 2001, p. 8). Por ello, sus ensayos reflexivos visibilizan, de una u otra forma, las construcciones de identidad juvenil y demuestran que dichas personas tratan constantemente de constituirse a sí mismas, a la vez que se enfrenta a un entramado de situaciones de discriminación etárea que vinculan su etapa en el desarrollo humano con el idealismo estético.

3 Se refiere a un "complejo articulado de signos que atraviesan el contexto cultural de la actualidad; en él confluyen dos series de acontecimientos: por una parte, al avance de la cultura de la imagen y, además, el encumbramiento de lo juvenil fetichizado por los lenguajes hegemónicos de la sociedad de consumo" (Margulis y Urresti, 1998: 15). Este concepto es aclarado también en Duarte (2006, p. 179), quién expresa que son "aquellas imágenes que circulan en nuestros imaginarios como modelos a seguir y que son mayoritariamente impuestos desde los medios dominantes de comunicación, socialización y poder”. 
Estos avances en la teorización efectúan críticas a las posiciones reduccionistas del ser joven, que están a favor de la estigmatización, del ocultamiento de realidades y de la sobrevaloración de lo negativo, y por el contrario; buscan opciones alternativas que permitan mirar el mundo juvenil en sus espacios de acción cotidianos, es decir, tal y como se construyen y re-construyen en la interacción con sus pares y el contexto inmediato en el que se desenvuelven.

En este sentido, se plantea que la singularidad que alberga la palabra "juventud" limita la condición de diversidad de las diferentes formas de vivir y convivir, que en un cierto instante puede malinterpretarse como una homogeneización (Margulis, 1998). Es por ello que se enfatiza en la pluralidad mediante el término "juventudes", categoría que abarca un conjunto de personas de diferente clase social, género, etnia, religión, lugar de residencia, además de incorporar las maneras de ser, sus actitudes y disposiciones ante la vida personal y colectiva.

\subsection{Participación política}

La participación política es reconocida en el imaginario social de acuerdo con su vinculación con lo electoral, reduciendo su ámbito de acción al ejercicio del sufragio como máxima representación del papel activo en la política ciudadana.

Esta forma de comprender la actividad en la política basa su implementación en instrumentos formales que los diferentes gobiernos han ido proponiendo a la sociedad civil para que se exprese, los cuales en definitiva han perdido grados de validez al ser considerados los resultados obtenidos manipulables. Además de concebir estas herramientas deficientes en el momento en que las personas manifiestan su insatisfacción con acciones del gobierno, este en muchos casos, invisibilizador del aporte ciudadano.

Esta ubicación teórica, limita el alcance de la participación política, cae en el juego de la discriminación de grupos sociales y la "deshistorización" de la política en su concepto más general.
Es por ello por lo que en este artículo se requiere reconocer que existen formas alternativas de participación política, que son comprendidas por Sermeño (2006, p. 28) como:

...tipos de participación que toman cuerpo bajo emergentes formas de movilización social o nuevas maneras de tematizar demandas colectivas e innovadoras capacidades de organización autogestiva de grupos e individuos con independencia del Estado. La sociedad civil y el espacio público como lugares de expresión de la autonomía de lo social son, pues, igualmente realidades que al expresar formas ampliadas de participación democrática anticipan con objetividad posibilidades de viabilidad a modelos alternativos de democracia.

De esa manera, la participación política se constituye en el requisito fundamental de aquellas sociedades que entienden los procesos democráticos como la opción política que toman las personas para incluirse en la sociedad y apelar dinámicamente por sus intereses colectivos. Esto se demuestra mediante manifestaciones populares, expresiones artísticas, organización de comités a favor de una demanda social, participar en partidos políticos (desde la parte formal), paros, espacios de discusión alternativos (calle, esquina del barrio, casa de un vecino/a, amigo/a o compañero/a), entre una diversidad amplia de opciones.

Desde esta concepción alternativa, la participación política alcanza su plenitud al proponerse como práctica contraria a la hegemonía, que puede desarrollarse desde un plano individual o colectivo. Pero su carácter primordial lo encuentra en la integración de movimientos o grupos sociales que logren consenso y apoyo mutuo a sus luchas, propiciando una coordinación social que brinde una oportunidad viable de modificar estructuras ideológicas dominantes.

Desde este punto, como se observa en la siguiente cita:

La participación política se concibe como un proceso de construcción social y colectivo capaz de integrar las interpretaciones que las personas 
tienen sobre ella, lo que causa deconstrucciones y reconstrucciones que buscan su adaptación al contexto social y político vivido. Se percibe diversa en el sentido de los posicionamientos políticos que cada sector le instaura en sus ejercicios. Un voluntariado en la Cruz Roja, una militancia en un partido político derechista o izquierdista, un integrante de alguna comisión religiosa, un militante en la defensa de los recursos naturales, son solo algunos ejemplos de los grupos que optan por participar pero que al mismo tiempo modifica el concepto de participación política ajustado a sus objetivos (Muñoz, 2011: 97).

Por lo tanto, la participación política adquiere importancia en la escena pública por su doble función, según lo expresa Bendit (1999), en cuanto a la manutención de la legitimidad del ordenamiento político del que se trate, como en relación con la capacidad de dichos sistemas para enfrentar y resolver problemas económicos, sociales y políticos. Ambas expresiones conducen al ejercicio del poder, entendido no como una abstracción u objeto inalcanzable, sino en su condición simple de pertenencia de todas las personas, puesto en la práctica cotidiana, interpretada como la fuerza personal de cada sujeto social.

De acuerdo con los planteamientos teóricos estudiados sobre la participación política, se puede definir como una actividad humana que hace referencia a la toma de decisiones con injerencia social, por medio de acciones colectivas dirigidas por un grupo social específico o en expresiones masivas de integración social. Alberga diversidad de posturas políticas (tradicionales o emergentes), las cuales justifican el actuar de cada grupo y la diversidad de sus manifestaciones en una realidad social concreta.

\subsection{Participación política juvenil}

Es de relevancia expresar que la participación política es concebida desde su postura más general, como la que comprende que toda acción humana conlleva un discurso político, con la intención de construir una vida de calidad, esto requiere indirectamente acciones para satisfacer deseos particulares y colectivos. Aquí se contempla el escenario cotidiano de expresión de las personas, en este caso las juventudes, que brinda la posibilidad de reconocimiento como sujetos sociales.

Esta manera de conceptualizar la participación política ha sufrido modificaciones en el imaginario colectivo, donde se relaciona con una democracia representativa, con procesos electorales y funciones gubernamentales que limitan su espacio de acción. De modo que a las personas se les juzga desde estereotipos sociales marcados por un supuesto "apolitismo", con el cual se censuran formas alternativas de organización. Entonces, se ocultan fenómenos sociales como la crisis de representación de los partidos políticos, actos de corrupción de gobernantes y descontento de la población por la política tradicional.

Generalmente, este supuesto "apolitismo" recae como un juicio recriminador sobre estos sujetos, logrando concebirle como: "un problema de la juventud, una constante para referirse críticamente a este como sector despreocupado y distante de los asuntos públicos, cuestionando su autoexclusión para participar en las instituciones de la democracia" (Alayza, 2006, p. 160). Con esto se olvida que este es un fenómeno nacional que apela a la totalidad de la población al incrementarse la desconfianza y reducir la participación en asuntos electorales y partidarios. Al respecto Calvo et al (2016) señalan que:

La actual concepción de participación juvenil apuesta por un espacio alternativo, con mayor inclusión en espacios públicos, como las políticas sociales, la vida cotidiana, el ejercicio de derechos y con mayor protagonismo del liderazgo de agrupaciones juveniles menos vinculadas con el espacio meramente ideológico político partidario. (p.102)

De acuerdo con este panorama, se puede identificar que la política tradicional ya no cumple a cabalidad con las necesidades y aspiraciones de inclusión que las juventudes esperan para participar activamente en la escena pública y política. Más bien, se inicia un proceso de búsqueda de acciones políticas, alejado de las visiones dominantes de esta práctica, concluyendo en una transformación de las 
estructuras hegemónicas que pretendían la reproducción de las generaciones en corrientes tradicionales de la política.

A partir de los principales hallazgos y reflexiones efectuadas por Duarte (1998) en su estudio, para comprender la práctica política particular de los jóvenes, se obtiene que esta es caracterizada por:

a) Un surgimiento sencillo basado en un intercambio con lo cotidiano, el grupo juvenil no posee una "evolución lineal", proponen métodos y prácticas de reconocimiento de las juventudes como protagonistas históricos, construir un sujeto joven con criticidad, identidad propia, claridad en lo que se quiere, conocedor de sus capacidades.

b) La práctica política se orienta a las necesidades y situaciones juveniles.

c) Se ha pasado de prácticas coyunturales-puntuales a acciones de largo plazo (p.45).

Estas características, propuestas por Duarte (1998), nos llevan a la tarea de pensar que las juventudes, al formar parte de los grupos poblacionales que históricamente han sido identificados en situación de desventaja social, comparten semejanzas en relación con las prácticas políticas ejecutadas, como: partir de necesidades, superar las prácticas coyunturales, rechazar su situación de discriminación, entre otras.

En este sentido, las agrupaciones juveniles, además de intentar modificar las imágenes prefijadas que se tienen de ellos, albergan condiciones de particularidad en sus prácticas políticas. Es por esto que se realiza un esfuerzo por citar algunas de las características particulares que posee la participación política juvenil, elementos que no pretenden ser estáticos, ni excluyentes de otras manifestaciones.

Al seguir esta línea argumentativa, se puede afirmar que las prácticas políticas que ejecutan las personas jóvenes están marcadas por un conjunto de códigos, lenguajes, símbolos y expresiones que definen cada acción participativa y pensamiento. Tal situación es representada en las agrupaciones juveniles mediante acciones como: la apropiación de espacios alternativos de reunión (calle, la esquina del barrio, el parque, bares bohemios) que son distintos a los tradicionalmente utilizados por los demás grupos sociales, además de una sensibilidad estética y política que permite desarrollar maneras específicas de expresión del pensamiento (grafitis, canciones, dibujos, fotografías) e imposición de tipos de moda que muestran sus actitudes hacia la vida y la sociedad.

Aunado a esto, se tiene que el proceso de socialización y el intercambio cotidiano de cada joven marcará ineludiblemente el deseo de agrupación y, por ende, el ejercicio de la participación política. Así, las interrelaciones con el grupo de pares irán perfilando las distintas agrupaciones juveniles y en cada una de ellas, un posicionamiento político específico.

Por ello, la participación política juvenil será comprendida como un proceso de construcción histórica y de un constante intercambio cotidiano que marca ineludiblemente la organización y participación juvenil. Esta participación está compuesta por identidades juveniles que marchan entre la simbología de las acciones, los planteamientos y la sensibilidad estética por imponer modas concordantes con sus pensamientos.

\section{Metodología}

La investigación se desarrolló en el periodo que comprende los años 2010-2011, mediante una metodología cualitativa, debido a que se buscó en todo momento adentrarse en la subjetividad de las personas jóvenes involucradas en el estudio, tomando como punto de partida sus experiencias cotidianas de participación política juvenil. En ese sentido, se concibe la metodología cualitativa como aquella forma de conocer la realidad social desde la propia perspectiva de los sujetos sociales, examinando el modo en que perciben y experimentan el mundo a partir de sus vivencias concretas (Taylor y Bogdan, 1984).

Las principales técnicas de recopilación de información fueron: la entrevista semi-estructurada y grupos focales a integrantes de seis agrupaciones juveniles existentes en el distrito central del cantón de San Ramón de Alajuela, 
Costa Rica. Se eligió este espacio geográfico, debido a la trayectoria histórica que ha tenido en cuanto a los procesos de participación política a nivel nacional.

La población del estudio estuvo conformada por treinta y un personas jóvenes participantes de seis agrupaciones pertenecientes a tres áreas de acción: institucionales (Comité Cantonal de la Persona Joven, Pastoral Juvenil), de adscripción cultural (Peña Cultural, Colectivo Artístico, Ecológico y de Economía Experimental- ECOARTE) y movilización o protesta social-política (Colectivo Garabito, Colectivo Mariposa). Las edades de las personas involucradas están entre los 18 y los 34 años 4 . Para seleccionar esta población participante, previamente se realizó una exploración preliminar de grupos organizados en el periodo del estudio, de los cuales se incluyó a las seis agrupaciones que cumplían con los siguientes criterios de selección:

- Colectivos conformados mayoritariamente por personas jóvenes.

- Disponibilidad para participar en la investigación.

- Grupos que tienen como espacio de reunión el distrito central del cantón de San Ramón.

- Representación equitativa según género.

- Agrupaciones activas en el periodo del 2010 al 2011.

Con el propósito de asegurar el acceso y la calidad de la información, con el consentimiento de las personas participantes en el estudio, se utilizó una grabadora durante el desarrollo de las entrevistas y los grupos de discusión. Seguidamente, las grabaciones fueron transcritas por el equipo investigador, para su posterior tabulación, ordenamiento e interpretación. Durante el momento de análisis, se seleccionó minuciosamente la información que resultó pertinente para responder al problema de la investigación y a cada uno de los objetivos específicos construidos. Esto se realizó mediante la elaboración de matrices de información distribuidas por categorías generales, que además de seleccionar los datos, permitió clasificarlos según las sub-categorías de análisis.

Como parte del estudio de resultados se llevó a cabo un exhaustivo proceso de reflexión a partir de los datos derivados de las técnicas de investigación, integrando permanentemente los aportes teóricos de los diferentes autores consultados y la posición epistemológica del equipo investigador sobre el fenómeno en estudio.

\section{Análisis de resultados}

El término participación, al igual que otros conceptos, pasa por la condición histórica que lo construye y reconstruye continuamente, adoptando diversas posiciones en el entendimiento cotidiano y científico, donde adquiere significados que dependen de cada individuo o grupo social.

Por estos motivos, en el presente apartado se busca comprender las concepciones que le atribuyen las agrupaciones juveniles a la participación política, esto a partir de las discusiones generadas en el grupo focal. Para ello, se toman como punto de partida las experiencias de cada participante en la investigación, las cuales se conciben como la base de los conocimientos previos que se poseen sobre la participación política.

Para comprender las significaciones que las juventudes le otorgan a la participación política se debe ir desagregando paulatinamente, iniciando en las concepciones que tienen los sujetos participantes ${ }^{5}$ sobre su papel en la política en general:

"Formar parte de algo" (Pedro, participante masculino del Colectivo Garabito).

"Diay como soy muy visual yo lo que veo es un montón de personas como con las manos alzadas como signo de liberación" (Antonio, participante masculino de ECOARTE).

\footnotetext{
4 Según la Política Pública de la Persona Joven en Costa Rica las personas jóvenes se ubican entre los 18 y los 35 años.

5 Con el propósito de respetar la confidencialidad de la información proporcionada por las personas participantes, los datos se presentan utilizando pseudónimos.
} 
"Yo creo verdad que participar tiene que ver con el verbo accionar, cuando vos estás haciendo, proyectándote estas participando dentro de una agrupación" (Lulu, participante femenina de Peña Cultural).

"La expresión de ideas, que digan su punto de vista, tiene que ser una actividad también donde usted pueda participar, realizar alguna obra o algún ensayo" (Ángel, participante masculino de Pastoral Juvenil).

"Yo digo que la participación realmente sería cuando usted se inmiscuye en algo, que lo que usted está haciendo por mínimo que sea tiene una proyección hacia algo" (Vinses, participante masculino de Comité Cantonal de la Persona Joven -CCPP-).

De acuerdo con lo afirmado anteriormente, el concepto sobre la participación gira en torno a dos sustantivos que la definen: la acción y la expresión. Estos se muestran como indispensables en las prácticas participativas, donde se reconoce que las personas tienen pensamientos propios ante las situaciones sociales y políticas, donde el simple hecho de expresar sus ideas debe ser reconocido como una inclusión en la sociedad. Aunado a ello, se comenta que la acción es el signo visible de la intervención, que es la capacidad que tienen las personas y los grupos de colocar los pensamientos en acciones concretas, las cuales tienen una proyección, que es el alcance de objetivos o la satisfacción de necesidades sociales.

Según estos sujetos, la participación amerita formar "parte de algo", identificarse con una causa o un grupo, es un "sentimiento" de inclusión, de sentirse parte importante de un proyecto o una comunidad, donde se acciona para alcanzar una meta que depende de las intencionalidades de una u otra agrupación.

Es así como se puede plantear que: "la participación supone ser parte del tejido de relaciones que se configuran por el entramado de la diversidad de intereses algunos afines, otros en conflicto en el espacio local, regional y nacional" (Molina, 2002, p. 29). Por lo tanto, el término "formar parte de algo" alude a que las personas somos seres sociales que requerimos de la interrelación, es decir, del vínculo con otras personas, y a pesar de que no estemos participando en una agrupación, estamos dentro de una sociedad, incluidos en un sistema determinado de participación:

"Yo voy a decir una frase de un autor Helio Gallardo, "no hay afuera social", o sea... que participo de una manera autónoma..., pero siempre por otras personas, hay una participación también, hay una colectividad también. Ser parte de algo: de un proyecto, de un proceso". (Marina, participante femenina de ECOARTE).

De esta forma, escuchar, pensar, actuar, analizar, denunciar, reflexionar son todos verbos que califican de una u otra forma dentro de la categoría de participación que construyeron las personas jóvenes, verbos que amplían los horizontes posibles de la conceptualización de dicha intervención social, al tomar en cuenta elementos, como por ejemplo: la escucha de un noticiero donde la sociedad se "informa" y asume una posición al respecto. Acciones como estas son consideradas por la juventud como una de las opciones que poseen las personas para participar.

A partir de ello, la participación puede ser concebida como: "una dimensión clave de la inclusión de los (las) jóvenes en la sociedad, pues a través suyo los (las) jóvenes expresan tanto sus posibilidades como sus deseos en la construcción de un futuro compartido" (Hopenhayn, 2004, p.11). Este autor reconoce que las juventudes desarrollarán acciones participativas con base en sus capacidades y motivaciones.

Teniendo presente lo anterior, se considera que el accionar en la política es una de las distintas maneras de ejercer la participación, la cual se identifica por González (1996) como la intervención de los ciudadanos para materializar intereses individuales y colectivos.

Aunque es importante señalar que existe un imaginario colectivo que hace introyectar en las personas una reducida interpretación de la participación política, que alude, a la condición de práctica política ligada al 
ejercicio del poder coercitivo y su relación con las clases dominantes; situación que afecta considerablemente las significaciones que pueden tener las personas sobre su papel en la política (Rauber, 2005-2006).

Para el caso de la juventud, se identificaron las primeras afirmaciones que tuvieron las personas sobre la participación política. Estas afirmaciones se ubican en dos grandes grupos: las prácticas partidarias e institucionales/gubernamentales y la acción humana, esta última con dos distinciones: la acción humana, basada en la construcción de acciones políticas en la vida cotidiana, y la acción humana relacionada a la contra hegemonía o reivindicación.

En el primer conjunto de afirmaciones realizadas por las personas participantes, se encuentran las frases vinculadas a la participación política partidaria o basada en el ejercicio de una práctica institucional o gubernamental, que presentan en parte el imaginario social dominante sobre la intervención política:

"Lamentablemente y aunque uno tiene que empezar a cambiar la mentalidad, participación política: votar, es lo que nos han metido a la cabeza desde la escuela, las votaciones presidenciales y es lo que nos han metido" (Pedro, participante masculino de Colectivo Garabito).

"Yo puse robo, por qué lo puse, porque los que están involucrados en eso que son organizaciones que luchan según ellos por los derechos humanos como cuartada de todo lo único que hacen es estarnos robando la libertad, la libertad de cualquier cosa que si yo quiero ir o estar en algún lugar me regañan" (Rodrigo, participante masculino de CCPP).

"Bueno yo tengo muy sucia esa palabra, muy contaminada... mi abuelo estuvo muy metido en eso y me ha dicho un montón de barbaridades de partidos, pero el asunto es que en lo personal yo tengo muy contaminada esa palabra, yo diría que son: acciones partidistas (politiquería), participación política yo diría que, con los ojos de experiencia de personas que conozco que están metidas en eso, yo diría que es algo no productivo" (Karey, participante masculino de Peña Cultural).

Esta forma de concebir la participación política se liga al imaginario colectivo que ha existido a través de los años, que relaciona este tipo de participación como un acto exclusivo de los procesos electorales y las acciones gubernamentales, resultando en un doble sentimiento: el reconocer el derecho que tienen las personas a decidir por medio del voto y la sensación de impotencia que irá con los procesos de corrupción y manipulación. Esta segunda reacción va en aumento debido a un proceso electoral debilitado, que día con día revela ante la sociedad sus intereses individuales y la minimización del poder popular. La situación anterior se comprende mediante Hopenhayn (2004) como:

Un proceso de desafección juvenil frente a las instituciones políticas y sus actores, así como también una desvalorización del régimen democrático como sistema de gobierno. Este último aspecto aparece vinculado a la percepción de que la democracia y su ejercicio no generan un sistema de igualdad de oportunidades. (p. 14)

Así, las personas jóvenes establecerán la relación de lo electoral-partidario desde una concepción negativa de la práctica política. Las experiencias que transitan en los recuerdos de personas que fueron engañadas en procesos electorales, son parte de los personajes de las historias que le contó el familiar a Karey, que han empezado a reconocer en la política una amenaza a los intereses de las comunidades que buscan ser escuchadas e incluidas en la toma de decisiones. Además, de identificar que son considerados objetos de la política, relacionados con datos fríos en las estadísticas que ubican a las personas entre votantes, abstencionismos, votos nulos, entre otros.

En este sentido, la participación política es interpretada por estas personas jóvenes como reduccionista de la acción popular que, en vez de reivindicar a los pueblos, busca depositar el poder en un grupo limitado de personas que ni satisfacen las necesidades colectivas ni poseen intenciones de hacerlo, como se observa a continuación: 
Esto significa que el proceso político es concebido como la lucha competitiva de las élites por los votos de un electorado implícitamente asumido como esencialmente pasivo, ignorante, falto de juicio, que a lo más practica una consideración instrumental de racionalidad económica; esto es, la transmutación del ciudadano en consumidor, el cual es, para colmo, víctima indefensa de la manipulación conductual más descarada, producto de la aplicación de las sofisticadas técnicas de la propaganda comercial (Sermeño, 2006, p.11).

De esta forma, las personas jóvenes se han formado en un contexto que da el calificativo de exclusiva a la participación política, hecha para los partidos políticos o instituciones gubernamentales, intervención que también se aleja de sus espacios inmediatos de acción e interrelación, logrando provocar que jóvenes mantengan como natural la manera de ver dicha categoría, creciendo los sentimientos de rechazo hacia ella.

Esta negativa se presenta debido a los acontecimientos de corrupción política y la deslegitimación que enfrenta la estructura del país, lo que resulta en una apatía en el hecho de ser parte de los procesos políticos electorales, generando una reacción de: "resistencia y oposición" (Duarte, 1998, p.69) por parte de las personas jóvenes, que no conciben el término participación política para describir las acciones realizadas por estos:

"Participación política también se puede hacer en otras instancias, pero yo le pondría otro nombre, la primera palabra que se me vino a la mente fue politiquería el asunto es cambiar esa palabra, yo creo que las acciones propias son las que cambian esa palabra, no ponerle nombre a las cosas sino nada más hacerlas. Si tengo que ponerle un nombre que se me ocurra ya, sin tiempo para pensarlo un buen rato, yo le diría GANAS (asociado al movimiento)" (Karey, participante masculino de Peña Cultural).

La tergiversación de los conceptos, que se ha producido por las instituciones socializadoras del país, provoca su rechazo en las personas jóvenes que, al mismo tiempo, en su actitud de repudio, reconocen que existen otras prácticas políticas que se han efectuado y se siguen ejecutando en los grupos y comunidades. La problemática que se presenta no es reconocer que existen prácticas políticas distintas a lo partidario, sino pensarse y actuar con motivación por este tipo de participación.

En este sentido, Hopenhayn (2004) plantea que el rechazo y el descrédito a organizaciones tradicionales de la política no le restan el valor que le asignan las personas jóvenes a la participación, entendida como: "mecanismo para la auto realización y obtención de logros” (p.14). Es decir, las personas actúan motivadas para satisfacer necesidades y alcanzar objetivos individuales y colectivos, por lo cual, las acciones e instrumentos serán concordantes con aquellas intencionalidades de la persona o grupo que las ejerza.

El referirnos a las acciones que son identificadas como participación política fuera del ámbito partidario, requiere de la exposición de un segundo grupo de afirmaciones que comprenden la práctica política como una acción humana. Sin embargo, este conjunto se fragmenta en dos distinciones: construcción de acciones políticas en la vida cotidiana y acciones relacionadas a la contra hegemonía o reivindicación.

La construcción de acciones en la vida cotidiana define a las personas como seres políticos que, en el transcurso de su vida, deben tomar decisiones y posturas que involucran un posicionamiento político de cómo concebir el mundo para interpretarlo desde sus experiencias concretas:

"Yo puse vida cotidiana porque yo creo que la política es la vida cotidiana desde que usted se levanta hasta que se acuesta, incluso podríamos decir que hasta lo que sueña puede ser muy político verdad...” (Marina, participante femenina de Colectivo Garabito)

"Yo solo puse necesaria porque la participación política es necesaria, somos entes políticos, todo lo que nos rodea es política no nos podemos escapar de ella, necesitamos la política para relacionarnos, para el accionar de una sociedad 
de un grupo, de la familia. Si es necesaria nos crea un compromiso, un ligamen con ella" (Ada, participante femenina de ECOARTE)

"Yo lo que puse fue munditos dentro del mundo, entonces es como nuestro mundito personal está dentro del mundo entonces que la política se hace tanto en el mundito personal como en el mundo, el mundo sería lo más oficial y en el mundito es lo más personal. El consumo es un acto político, yo voy y compro Coca Cola estoy hablando de mi posición política también" (Marina, participante femenina de ECOARTE).

Con respecto a la participación política, vista desde un plano directo, con las personas en los ámbitos cotidianos, se reconoce que su puesta en práctica pasa por el carácter cuestionador de los conocimientos y la toma de una posición personal ante ellos. Posición que no se califica como positiva o negativa, puesto que, puede transitar en ambas dimensiones dependiendo del individuo o grupo que le adquiera para su ejecución. Se reconoce con ello que toda persona se encuentra en la capacidad de realizar participación política, debido a que esta se construye en los espacios cotidianos de acción, rompiendo con el imaginario colectivo de limitar el espacio a instancias gubernamentales o a procesos electorales; más bien abriendo el horizonte de significación que integra cualquier tipo de práctica política realizada por el ser humano que posea una posición, una acción o una decisión para participar.

La interpretación proporcionada por personas jóvenes identifica la no acción y los silencios como prácticas políticas importantes que reflejan el sentir de la población. De esta forma, cada aspecto, etapa o circunstancia de la vida de una persona tiene una connotación política de ser, donde se podría plantear que la participación se comprende a partir de espacios representativos, en otras palabras, se posee una instancia particular en la que se construyen posiciones políticas individuales, con cada persona en su realidad cotidiana, con sus razonamientos propios e influenciados por el contexto inmediato.
Por otra parte, debido a los intereses o motivaciones en común, se crean colectivos o grupos que comparten un ideal u objetivo por seguir, conformando un movimiento popular que en algunos casos permite la articulación de unos grupos con otros, en búsqueda de un mismo fin: la inclusión social. Estas interrelaciones se dan con base en múltiples prácticas políticas que explican el universo de la participación política.

Vinculado con la reflexión anterior, a continuación se describe un conjunto de frases que incluyen la concepción de la participación política como acción humana, pero que se relacionan con la contra hegemonía o reivindicación social:

"Yo puse desobediencia civil, inspirado en nuestro grupo... ejemplo: siempre estuvimos con la idea de hacer parchecitos desprestigiando un montón de marcas empresariales que utilizan a la humanidad para enriquecerse, que de sus productos no se saca nada beneficioso y bueno toda esa propaganda como corrompe nuestra mente, verdad" (Juan, participante masculino de Colectivo Garabito).

"Yo puse integrarse, cambio estructural o movimiento, que se me ocurrió cuando usted estaba hablando; ya que cualquier acción que uno genere va a tener un cambio" (Tere, participante femenina de Colectivo Mariposa).

"Yo puse que es ser consciente en mi proceso y tener sensibilidad a los temas de interés local y nacional, para poder actuar de acuerdo con nuestras convicciones y del bien común, yo creo que, lo que es bueno para todos es bueno para uno, lo que es bueno para uno es bueno para todos. Es tener ese interés de ver lo que está pasando, que nos está afectando. Yo creo que eso es lo que no tenemos, una capacidad de reacción de los ticos hacia las políticas verdad, que hay a nivel nacional" (Josefa, participante femenina de ECOARTE). 
Estas expresiones cumplen una función de enfrentamiento al sistema imperante y de la ejecución de acciones que demuestren el descontento popular, esto mediante la construcción de alternativas para expresarse y reaccionar ante las desigualdades que existen en torno a la inclusión social y acceso al poder. Se reconoce que se debe crear un proceso de concienciación sobre las realidades locales y nacionales para posicionarse ante ellas.

Aunque la teoría y la práctica demuestran que no toda participación política es reivindicación popular, existen algunas prácticas que albergan en sus visiones o aspiraciones el pensamiento contra hegemónico, demostrado en frases como la de Juan ("desobediencia civil”), que remiten a conductas denunciantes sobre actos inhumanos y de corrupción en instituciones, empresas o personas que buscan el beneficio individual. Acciones observadas por la sociedad como acto de rebeldía.

Esta práctica política no generalizada, se encuentra como una opción que podría brindarle a la intervención en la política, la oportunidad de generar cambios o modificaciones a las estructuras ideológicamente establecidas. Los grupos o personas que dirigen sus acciones por ese objetivo, tienen una ideología e intereses particulares que los ubican en el universo de transformaciones, las cuales pueden o deben realizarse:

"Yo puse actuar dentro de una ideología (llena de intereses del poder) pero aprovechando los recursos y facilidades que podría tener... Con las peñas se hace un cierto tipo de política, porque llegamos a influenciar a la gente, que ellos conozcan el pensar, el actuar de todo esto digamos, todos los valores que se trasmiten en la peña y eso es parte de la política también" (Pinto, participante masculino de Peña Cultural).

De esta manera, los sujetos participantes identifican como indispensable en la labor política la claridad de posicionamientos y la selección de un campo de acción, que pueda visibilizar la existencia de concordancia entre lo razonado y lo realizado en actividades de los grupos. Es indispensable manifestar que estos jóvenes, a pesar de que albergan deseos de efectuar cambios estructurales a gran escala, reconocen que el comienzo se encuentra en aquellas pequeñas acciones que se ejecutan en los espacios cotidianos.

La ideología se identifica entonces como uno de los elementos indispensables para realizar alguna práctica política dentro de agrupaciones juveniles, la cual se interpreta de acuerdo con el discurso de los sujetos participantes, como lo es la corriente de pensamiento que un determinado grupo elige para direccionar sus acciones. Este discurso integra todos aquellos intereses colectivos que se convierten en códigos característicos de la dinámica grupal interna, y estos aspectos, serán visibilizados en las banderas de lucha adoptadas por el colectivo. Esto se ejemplifica con las pretensiones reconocidas en cada agrupación juvenil participante: expresiones culturales al alcance de todas las personas, valorización del trabajo manual, apertura de un espacio particular de mujeres que reivindiquen la discusión de temas tabúes, reconocer el papel del joven en la sociedad, apostar a la religiosidad en forma juvenil y apoyar a movimientos sociales y ambientales, apostando a estilos de vida alternativos.

Para concluir se debe visibilizar que los aportes brindados por los participantes se distinguieron en dos grupos de expresiones diferenciados: quienes participan de una agrupación formal y aquellas que se incluyen en una agrupación informal.

Las personas incluidas en agrupaciones juveniles consideradas formales se mantuvieron en el primer grupo de afirmaciones, grupo que le designa a la participación política aquellas acciones partidarias, institucionales o gubernamentales. Estos jóvenes visibilizan constantemente una relación entre política, legislaciones, reglamentos y ejercicio del voto. Aunque se debe acotar que dentro de estas agrupaciones se encontraron jóvenes que no comparten ese pensamiento y más bien, vuelven su mirada a prácticas políticas ampliadas a la totalidad de la población (sin embargo, son la minoría del grupo).

Por otro lado, encontramos a las agrupaciones informales que incluyen los grupos de la adscripción cultural de movilización o protesta social-política. La mayoría 
de sus integrantes manifiesta la vinculación de la participación política con acciones humanas cotidianas o reivindicativas. Relación que se ve fundamentada por el proceso organizativo y participativo efectuado por dichos grupos. Es decir, que las agrupaciones juveniles informales, al movilizarse dentro de la sociedad de una forma independiente a una figura institucional, adoptan otro tipo de concepciones/acciones políticas y se les visibiliza en otra realidad social, entendiendo que la participación política desde sus experiencias puede desarrollarse en diferentes espacios o ámbitos de la vida en sociedad, como se afirma a continuación:

Se trata de señalar aquí, enfáticamente, que no es que los jóvenes sean apáticos, ni ausentes de la participación como quiere hacernos creer cierto tipo de discurso des-movilizador y, por supuesto, sin intensión de convertir estas páginas en apología de los jóvenes, puede afirmarse, a través de una ya larga trayectoria de investigación empírica que los jóvenes están inaugurando nuevos lugares de participación política, nuevos lugares de enunciación, nuevos lugares de comunicación (Reguillo, 2000, pp. 124-125).

De acuerdo con las experiencias investigativas de Reguillo, esta reconoce que los procesos de globalización que se vienen desarrollando han intervenido la noción y adquisición de los espacios, lo que denomina como invención del territorio. Esta invención remite a la construcción-apropiación que realizan las personas jóvenes de los lugares, brindándole significados distintos a los reconocidos socialmente. Desde allí, lugares como el kiosco del parque, que son utilizados por algunas de las agrupaciones juveniles estudiadas para realizar sus actividades o eventos, adoptan el significado o la función que le impregna cada grupo.

No obstante, se debe expresar que, a lo interno de cada una de estas agrupaciones informales, se identificaron algunos conocimientos e integrantes que han sido permeados por el imaginario colectivo popular, entendiendo aún la práctica política como un asunto privilegiado de la clase política del país, basado en corrupciones y manipulaciones.

\section{Reflexiones}

Al tener presente las discusiones que se han efectuado, se pretende aportar una nueva significación de las prácticas políticas, que se amplía para vincular las acciones que se han creado en la sociedad y en específico, para comprender el accionar de las agrupaciones juveniles.

Por ello, la participación política, interpretada por el equipo investigador con base en las aportaciones de la población informante, será conceptualizada como una acción humana que se desarrolla individual o colectivamente y que posee un conjunto de objetivos, intereses o necesidades, las cuales responden a posturas políticas, cuya motivación principal es ser reconocido como actor o actriz social. Lo anterior remite al ejercicio del poder y a la inclusión en la toma de decisiones, ya que contempla la acción y la expresión política en busca de la incidencia o proyección social.

Esta conceptualización se crea pensando en un sentido amplio e incluyente de las diferentes manifestaciones políticas desarrolladas por las personas jóvenes, que pretende contener en sí misma las variaciones existentes en la participación política.

Se demuestra con lo expresado por las personas jóvenes, que en la sociedad costarricense se mantienen tanto las posiciones alternativas como las tradicionales a la hora de definir el concepto de participación política. Además, se afirma que factores externos (escuela, familia, relación de pares, la agrupación en la cual se participe) influyen en las visiones de mundo de cada joven y en las acciones participativas que se desarrollan.

De esta manera, la participación política juvenil será adoptada, introyectada y ejecutada a partir de las definiciones construidas por cada sujeto o grupo social en su realidad inmediata, dándole un tono distintivo dependiente de las intencionalidades y visiones que se posean. Estas serán modificadas por las coyunturas que se den, reelaboradas en los escenarios cotidianos en que habitan las personas. 
Otra conclusión relevante que se identificó durante el proceso investigativo, es como la participación política juvenil en las agrupaciones participantes se encuentra mediada por la centralidad que tiene el trabajo y/o el estudio en las personas jóvenes, dificultando en ocasiones una participación sustantiva en estos espacios grupales.

Además, se evidenció una importante centralización de las agrupaciones juveniles en el distrito central del cantón de San Ramón, lo que dificulta su involucramiento activo debido a dificultades de acceso por motivos de distancia geográfica y carencia de servicios de transporte público para trasladarse desde la comunidad donde residen con su grupo familiar, a las actividades colectivas de las agrupaciones estudiadas.

\section{Referencias bibliográficas}

Alayza, A. (2006). Hijos de su tiempo: notas sobre jóvenes y participación política. En Toche, E. (Compilador), Perú hoy: nuevos rostros en la escena nacional (s.d.). Lima: Centro de Estudios y Promoción del Desarrollo.

Bendit, R. (1999). Participación social y política de los jóvenes en países de la Unión Europea. (s.d.) Reunión del grupo de trabajo “Juventud” CLACSO.

Calvo, A., Muñoz, A., Torres, Y., Zamora, M. (2016). Aproximaciones teóricas, metodológicas y ético-políticas sobre la participación juvenil en el cantón de San Ramón. Revista Pensamiento Actual, 16 (26), 101-112.

Duarte, K. (1998). Alternativas Construidas desde las y los jóvenes pobladores: voces de oposición y resistencia. En Escuela de Formación-Ecuador y Departamento Ecuménico de InvestigacionesCosta Rica (Ed), Juventudes Populares: el rollo entre ser lo que queremos o ser lo que nos imponen. Colectivo Educación Popular Juvenil NEWENCE (s.d.). San José: Editorial "Tierra Nueva".
Duarte, K. (2006). Discursos de Resistencias Juveniles en Sociedades Adultocéntricas. San José, Costa Rica: Departamento Ecuménico de Investigaciones.

González, E. (1996). La participación ciudadana en la gestión local. En: Manual sobre participación y organización para la gestión local. Bogotá, Colombia: Ediciones FORO Nacional.

Hopenhayn, M. (2004). Participación Juvenil y Política Pública: Un Modelo para Armar. Trabajo presentado en el I Congreso de Asociación Latinoamericana de popular. ALAP. CaxambúMG, Brasil. 18-20 de septiembre de 2004.

Krauskopf, D. (2003). Participación social y desarrollo en la adolescencia. 3ra. Edición. San José, Costa Rica: Fondo de Población de las Naciones Unidas.

Margulis, M. (2001). Juventud: una aproximación conceptual. En Solum Donas Burak (compilador), Adolescencia y Juventud en América Latina, (s.d.).

Margulis, M. y Urresti, M. (1998). La construcción social de la condición de juventud. En (s.d.), Viviendo a toda: jóvenes, territorios culturales y nuevas sensibilidades. Págs. 1-22. Departamento de Investigaciones Universidad Central. Santafé de Bogotá: Siglo del Hombre Editores.

Molina, M. (Diciembre, 2002). Gestión local, municipalidades y participación ciudadana. Revista Costarricense de Trabajo Social, 1(14), 26-34

Muñoz, A. (2011). Participación política juvenil: un estudio exploratorio con agrupaciones juveniles existentes en el distrito central del cantón de San Ramón, Alajuela. (Tesis de licenciatura). Universidad de Costa Rica, Sede de Occidente, San Ramón.

Rauber, I. (2005-2006). Desafíos actuales de la política. Revista Pasado y Presente XXI, (1), 6-23. 
Reguillo Cruz, Rossana (2000). La intervención del territorio: procesos globales, identidades locales. En: Martín-Barbero, Jesús y otros (2000). Umbrales. Cambios culturales, desafíos nacionales y juventud. 1ed. Corporación Región. Medellín, Colombia.

Samper, M. (2001). Metodologías convergentes e historia social del cambio tecnológico en la agricultura. 1ed. San José, Costa Rica: Progreso Editorial.

Sandín, M. P. (2003). Investigación cualitativa en educación: fundamentos y tradiciones. 1 ed. Madrid: McGraw-Hill Interamericana de España.

Sermeño, A. (2006). Democracia y Participación Política: Los retos del presente. Andamios: Revista de Investigación Social, Universidad Autónoma de la ciudad de México. 2(4), 7-33.

Taylor, S., \& Bogdan, R. (1984). Introducción a los métodos cualitativos de investigación. Primera edición. Buenos Aires, Argentina: Paidós Studio. 